Article

\title{
Compaction Model for Shale in Differences of Geological Ages Using A 3D Empirical Relationship in Northeastern Thailand
}

\author{
Avirut Puttiwongrak ${ }^{1, *}$, Syukratun Nufus ${ }^{2}$, Chaiyaphruk Bunprasert ${ }^{3}$, Pham Huy Giao ${ }^{4}$, Sakanann Vann ${ }^{5}$ \\ Thongchai Suteerasak ${ }^{6}$, and Nophea Sasaki ${ }^{7}$
}

1 Assistant Professor, Geotechnical and Earth Resources Engineering, Asian Institute of Technology, Pathumthani, Thailand, corresponding: puttiwongrak.a@gmail.com*

2 Master Student, Faculty of Technology and Environment, Prince of Songkla University Phuket Campus, Phuket, Thailand; nsyukratun@gmail.com

3 Doctoral Student, Geotechnical and Earth Resources Engineering, Asian Institute of Technology, Pathumthani, Thailand, corresponding: chaiyaphruk.b@gmail.com

4 Associate Professor, Vietnam Petroleum Institute, Hanoi, Vietnam; giaoph@pvu.edu.vn

5 Doctoral Student, Faculty of Technology and Environment, Prince of Songkla University Phuket Campus, Phuket, Thailand; sakanannvann1992@gmail.com

6 Associate Professor, Faculty of Technology and Environment, Prince of Songkla University Phuket Campus, Phuket, Thailand; thongchai.s@phuket.psu.ac.th

7 Professor, Natural Resources Management, Department of Development and Sustainability, Asian Institute of Technology, Pathumthani 12120, Thailand; nopheas@ait.asia

* Correspondence: puttiwongrak.a@gmail.com

\begin{abstract}
Shales are well known for their strong anisotrophic properties. The classical Athy's model on the exponential porosity reduction with the depth commonly uses based on localities only. Shale compaction curve affects the results of the basin modeling as it is important input data, thus the standard compaction curve of shales needs to be established. This study provided a new data and complies available data of Thailand shales to propose the new empirical relationship among porosity, burial depth, and geological age. The numerical data of the geological time were estimated by the application from the relationship of velocity and depth in each geological ages. The variation of the Thailand shale data due to the different geological ages was found in this study. Finally, the standard curve of shale compaction proposed by Puttiwongrak et al. [9] was examined and confirmed by this research findings.
\end{abstract}

Keywords: Shale compaction; Geological age; Thailand shale; Compaction model; Standard curve

\section{Introduction}

Shale is a clastic rock formed from small clay particles; the fluid absorbed by certain clay minerals in the shale is affected by porosity which is an important parameter for analyzing shale compaction. Apart from porosity, several factors can affect the compaction process, such as pressure, the burial depth of sedimentary, as well as many studies also added that compaction is also strongly related to the burial time [1-3]. Shale reserve geology is highly complex in many Asia Pacific countries. Asia Pacific countries have considerable shale potential, in addition to China, Australia, Pakistan, and India which are countries with large shale potential in the world, the US Energy Information Administration (EIA) also highlight Thailand, Indonesia, and Mongolia as other Asian Pacific countries with significant shale potential [4].

In addition, shale compaction is an important phenomenon in sedimentary basins, the muds have higher initial porosity relative to coarser grains influencing the mechanical compaction than other sediments [5]. The mechanical compaction of the shale is different from the sandstone and the carbonate rocks. There, the mechanical compaction, 
which is dominant at shallow depths, is the most significant process for shale dominances.

Porosity-depth curves are important tools to investigate compaction processes as input data for basin modeling, the porosity-depth curves (mechanical compaction) affect the results of the basin modeling in several ways [6]. The porosity-depth trends are essential. The most widely used model is empirical relationships between the porosity and the depth. The classical Athy's model [7] on the empirical equation of exponential porosity reduction with depth has been widely used in a large number of studies for the shale compaction [8]. However, there are large variations in the porosity-depth curves of the mechanical compaction for shales [8-10], several factors may play an important role in porosity change with depth, e.g., temperature, geological age, clay diagenesis, overpressure, etc., resulting in the scatter plots of combined shale data $[3,9,11-14]$. Nowadays, various porosity-depth trends for shales [8] have been proposed based on empirical localisms. The standard model for sandstones is derived usually, extending the application to shales is not successfully robust.

The sediment depositions, uplift sequences, and diagenetic effects produce the porosity reduction in the term of time-varying, therefore, the geological time is currently applied for simulating advanced basin models [15]. The very few studies that have influenced a scatter of the porosity-depth plots for shales are particularly important. Early studies from Burst [16], who is a pioneer in studying the effect of the geological ages on shale compactions, concluded that the porosity of shales tends to reduce with increasing geological age. Furthermore, Puttiwongrak et al. [9] emphasized the effect of geological ages by re-plotting porosity-time plots to quantify the porosity changing with time at the same depth. The relationship among porosity, burial depth, and geological age was first established. However, the research findings of the previous studies on the time effect were done by geological variations of shale data, an attempt to holding geological constant while considering the relationship of porosity, depth, and geological age is needed to be clarified. Moreover, the compaction models of the shales are not well established.

This study provides new data and compiles available data of Thailand shale compactions based on geological age classifications, especially the mechanical compaction. The objective of this study is to confirm the variations in the porosity-depth curves as a function of geological ages in shales. Then the research findings propose the empirical relationship among porosity, depth, and geological age. The new shale compaction models in each geological age are established based on earlier work by Puttiwongrak et al. [9] and the empirical analysis is carefully described.

\subsection{Geological Setting}

The geological setting of Thailand is divided into several regions with different geological and lithological histories in an age range from Precambrian in Paleozoic era to Quaternary in Cenozoic era. Hydrocarbons in Thailand were discovered and produced from the Tertiary basins which are groups of the Cenozoic era and pre-tertiary basins included Triassic in the Mesozoic era and Permian in the Paleozoic era. Tertiary basins are distributed in several parts of Thailand, onshore (north, central, and south) and offshore (the Gulf of Thailand and the Andaman Sea). Pre-tertiary basin mainly situated in northeastern Thailand is made up of sedimentary rocks dating from Carboniferous to Tertiary $[17,18]$. Thailand has significant shale potential, mostly located in North-Central and Northeast of Thailand, in the Khorat, the North Intermontane, and the Central Plain sedimentary basins. These shales can be locally thick, organic-rich, dry gas prone, deeply buried, and overpressured [19].

This study used the data from four local basins located in Thailand, i.e Phetchabun basins in North Thailand, Mukdahan, Kuchinarai, and Phu Din in Northeast Thailand as shown in Figure 1. Each locations have its own geological age, the detail about this also provide in Table 1. 


\section{Data Collection}

The dataset of this study is composed of 169 data of shale formations from 4 areas in northeastern Thailand (Figure 1). Four study areas were selected based on the availability of porosity, burial depth, and geological age information for shale formations. Collectively, this study selected the data of broadly different ages covering a sufficiently wide range of burial depth. Based on well-logging data supplied by the Department of Mineral Fuel of Thailand (DMF) are from Paleozoic to Cenozoic ages and at a depth between 280 and $1100 \mathrm{~m}$ below ground surface.

Porosity data were calculated from the wireline density log (RHOB) using 2.762 $\mathrm{g} / \mathrm{cm}^{3}$ as the matrix density and $1.000 \mathrm{~g} / \mathrm{cm}^{3}$ as water density, and depth data are given in meter below the ground surface. However, the time data are in the geological ages, there are no numeric data of geological ages obtained from the DMF. Therefore, the numeric data of geological ages were estimated as discussed in the further section. The dataset is summarized in Table 1.

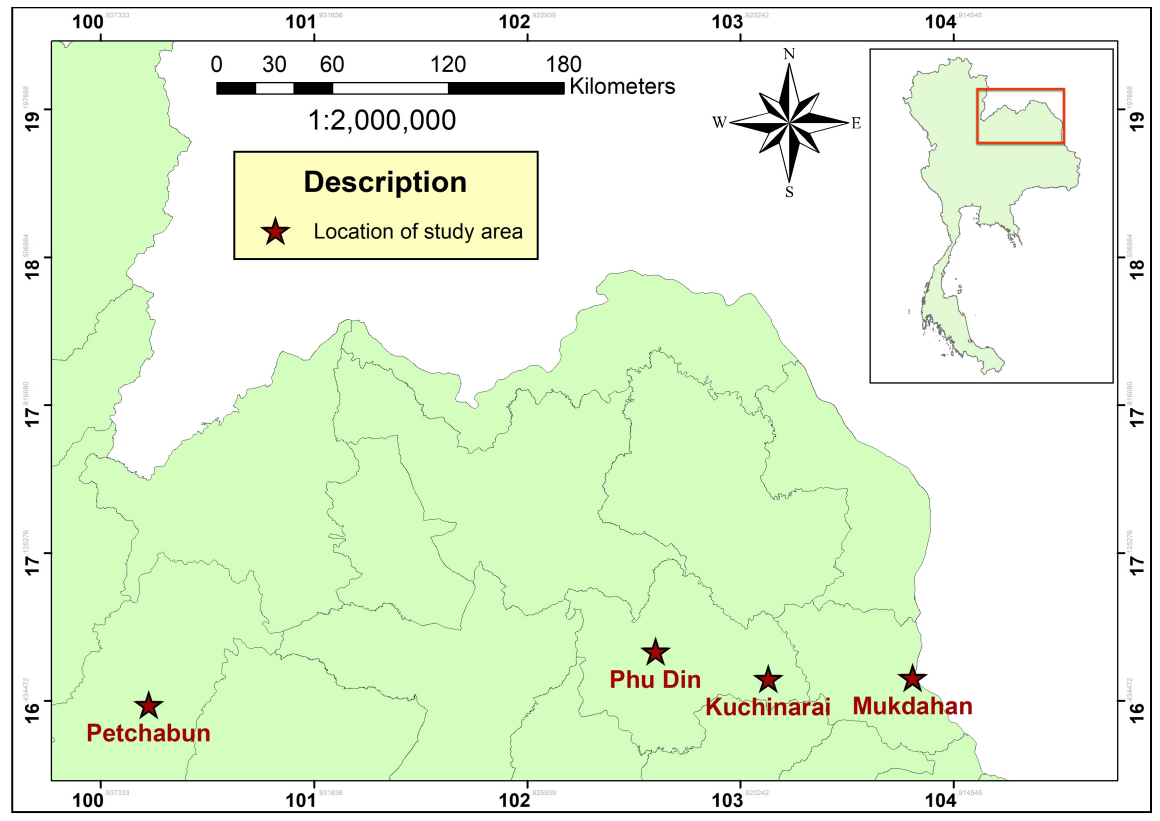

Figure 1. The location of data collection for this study

Table 1 Dataset list for this study

\begin{tabular}{cccccc}
\hline Location & Porosity & Depth $(\mathbf{m})$ & $\begin{array}{c}\text { Geologi- } \\
\text { cal Age }\end{array}$ & Total Data & $\begin{array}{c}\text { Estimation } \\
\text { Time (Ma) }\end{array}$ \\
\hline Petchabun & $12.1-29.4 \%$ & $285-1100$ & Cenozoic & 136 & $24.4-40.6$ \\
Kuchinarai & $4.8-14.5 \%$ & $503-686$ & Mesozoic & 14 & $73.6-78.1$ \\
Mukdahan & $3.2-6.4 \%$ & $823-869$ & Mesozoic & 3 & $73.5-73.8$ \\
Phu Din & $22-4.8 \%$ & $280-970$ & Paleozoic & 16 & $231.8-478.9$ \\
\hline
\end{tabular}

\subsection{Conventional Porosity-Depth Plot}

For quantifying the compactional scatter of shale data from northeastern Thailand, the dataset was plotted by the porosity-depth plot as shown in Figure 2. The compaction of shales is defined by porosity reduction during burial, the shale mechanical compaction of porosity reduction uses mostly exponential function as the conventional model to represent the compaction curve of shales [20]. However, the exponential func- 
tion proposed by Athy (1930) [7] as described in Eq. (1) was not fitted to the Thailand shale data $(r$-square $=0.0031)$ in order to obtain compaction curves. Figure 2 shows a trend of scattered data points at the entire depth, the porosity-depth curves at the same lithology and depth but from different areas have differences in the porosity of more than $20 \%$,

$$
\phi=\phi_{o} e^{-c z}
$$

where $\mathrm{c}$ is a constant, generally known as the compaction coefficient, $\mathrm{z}$ is burial depth, $\phi$ is porosity in-depth $z$, and $\phi_{0}$ is the initial porosity (at the surface).

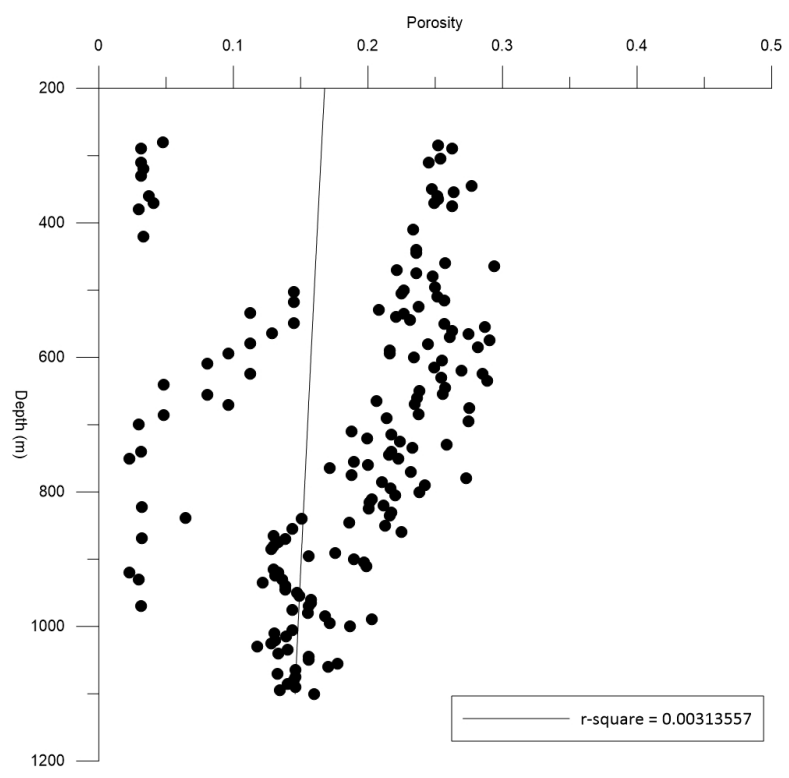

Figure 2. Thailand Shale porosity-depth in conventional compaction curve

\subsection{Estimation of Geological Age Data}

In this study, new data is provided based on the different geological ages of the Paleozoic, Mesozoic, and Cenozoic ages. The numeric data of each geological age were not available, but a numeric estimation of geological age was analyzed by examining the relationship among velocity, depth, and geological age as suggested by Faust [21]. Firstly, the velocity data were calculated by the relationship between velocity $(v)$ and depth (z) using the Eq. (2), (3), and (4) for the Cenozoic, Mesozoic, and Paleozoic datasets, respectfully, as shown in Figure 3. The modified plots from Faust [21] in Figure 3 give the relationship of the velocity and depth with the r-squares equal to $0.6253,0.7701$, and 0.9414 for each geological age (Cenozoic, Mesozoic, and Paleozoic, respectively) [21].

The equations for velocity as a function of depth in each geological age classification (Cenozoic, Mesozoic, and Paleozoic ages) are expressed below,

$$
\begin{aligned}
& v_{C}-0.434 x+3269.4 \\
& v_{M}=0.6325 x+2396 \\
& v_{P}-0.412 x+2096.5
\end{aligned}
$$

and the relationship of velocity, depth, and geological age in years: 


$$
\mathrm{T}=\left(\frac{v}{a}\right)^{6} \times \frac{1}{z}
$$

Where $\alpha$ is given presently the value of 46.55 and is numerically equal to velocity in meter per second when $\mathrm{TZ}=1$. Finally, the numeric data of the geological ages were calculated by Eq. (5) using the depth data from Table 1.

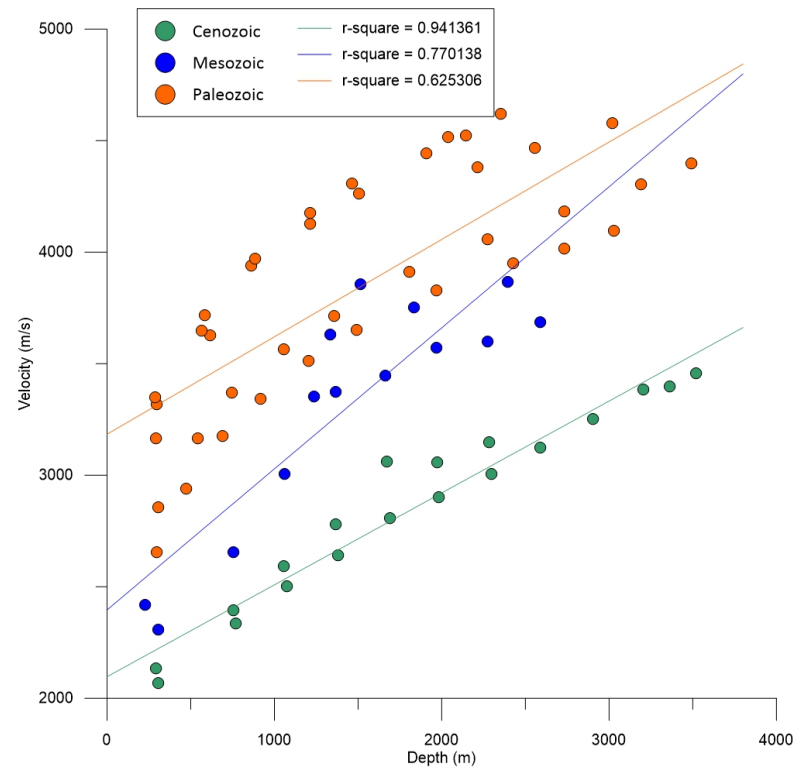

Figure 3. Velocity as a linear function for each geological age, Cenozoic (green), Mesozoic (blue), Paleozoic (yellow) modified plots from Faust [21]

\section{Analysis Method}

In this study, the compaction curve for shale, which is empirically determined by the porosity-depth plots, has been classified based on the different geological ages representing the effect of time on shale compaction (Fig. 4). The porosity-depth data in Cenozoic ages mean the data in the age range of 65 million years up to now, while the Mesozoic data are in the age range of $250-65$ million years. The Paleozoic data are in the age older than. Then, the empirical model was analyzed to fit the data among porosity, depth, and geological age for the Cenozoic, Mesozoic, and Paleozoic datasets, respectively.

A simple way to analyze the correlation among the data of porosity, burial depth, and geological ages as the statistical variables, the coefficient of the determination ( $r$ square) was computed as follows.

$$
r-\text { square }=\frac{\Sigma\left(\phi_{\text {data }}-\phi_{\text {model }}\right)^{2}}{\sum\left(\phi_{\text {data }}-\bar{\phi}\right)^{2}}
$$

where $\phi_{\text {data }}$ designate the porosity data as shown in Table $1, \phi_{\text {model }}$ is the predicted porosity from the compaction model, and $\bar{\phi}$ is the mean value of the statistical variable $\Phi$. The r-square is always comprised between 0 and 1 . The larger its value is the better the correlation between the observed and model data.

The mathematical formalisms of the porosity-depth-time relationships in which the data classification is based on each geological age (Cenozoic, Mesozoic, and Paleozoic ages) were established in northeastern Thailand shale. Finally, the new compaction model in a term of porosity as a function of depth and geological age were fitted to all data. 


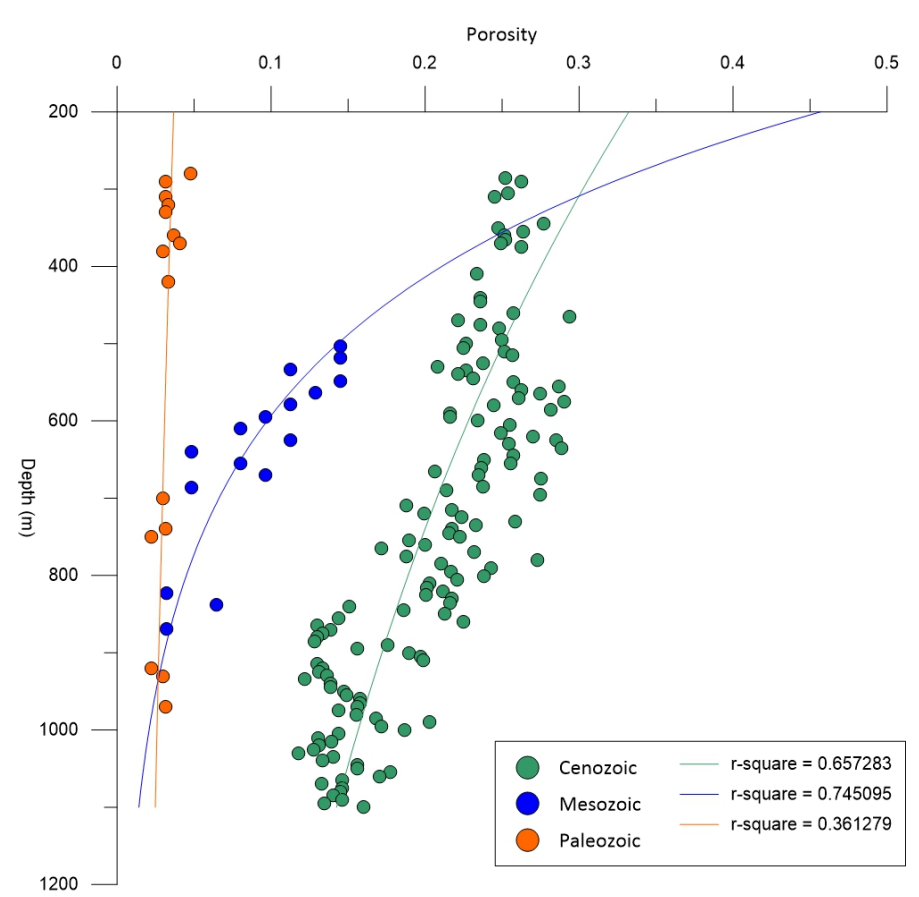

Figure 4. Thailand Shale porosity-depth classified for eaach geological age Cenozoic (green), Mesozoic (blue), Paleozoic (yellow)

\section{Results and Discussions}

\subsection{Effect of Time on Shale Compaction}

Based on the plot of the porosity-depth relationship (Figure 2), the fact that shale porosities from northeastern Thailand scatter considerably with depth and cannot be able to fit with the conventional model of the exponential function [7].

Using the geological age classifications, the data show better fits with Athy's model in the porosity-depth plots as shown in Figure 4. This relationship quantitatively supports the idea from the previous research of Puttiwongrak et al. [9]. A difference in the initial porosity $\Phi_{0}$ of $40.11 \%, 98.97 \%$, and $4.00 \%$ at the surface is seen for Athy's trends of Cenozoic, Mesozoic, and Paleozoic ages, respectively. Despite the small numbers of the r-square in some geological ages (0.6572, 0.7450, 0.3612, for Cenozoic, Mesozoic, and Paleozoic, respectively) this classification provides the quantitative empirical relationship of geological ages and porosity-depth plots. Therefore, this relationship is very helpful for analyzing the empirical model among porosity, depth, and geological age as discussed in the further sections.

\subsection{Empirical Model of Geological Age Classification for Thailand Shale Compaction}

Looking back to the porosities plotted versus burial depth for shales in northeastern Thailand, an empirical relationship of porosity, depth, and geological age can be found within Cenozoic, Mesozoic, and Paleozoic classifications. The empirical models of each geological ages, i.e., Cenozoic, Mesozoic, and Paleozoic data, were re-fitted by the multilinear regression (Fig. 5) instead of Athy's model, the compaction models with each geological age classifications are expressed:

- Cenozoic Age $(\mathrm{T}<65 \mathrm{M}$ years ago):

$$
\ln \phi_{C}-0.3458-0.0014 z-0.0342 T
$$

- Mesozoic Age $(65 \mathrm{M}<\mathrm{T}<250 \mathrm{M}$ years ago): 


$$
\ln \phi_{M}=-5.1324-0.0032 z+0.0627 T
$$

- Paleozoic Age ( $\mathrm{T}>250 \mathrm{M}$ years ago):

$$
\ln \phi_{P}=-6.0638+0.0012 z+0.0049 T
$$

Fitting equations (7), (8), and (9) to the dataset based on the geological age classification give the relationship of the porosities as a function of depth and time which the rsquares are 0.7160, 0.7570, and 0.5421 for Cenozoic, Mesozoic, and Paleozoic data, respectively (Figures 5a, 5b, and 5c). The models of Eqs. (7), (8), and (9) show to produce higher r-squares than Athy's model in each geological age as compared between Figures 4 and 5. Older shales in ages are due to long geological processes (deposition, diagenesis, erosion-uplift, etc.), thus they will also contribute to lower initial porosities. The influence of time on the shale compaction is incorporated in the coefficients.
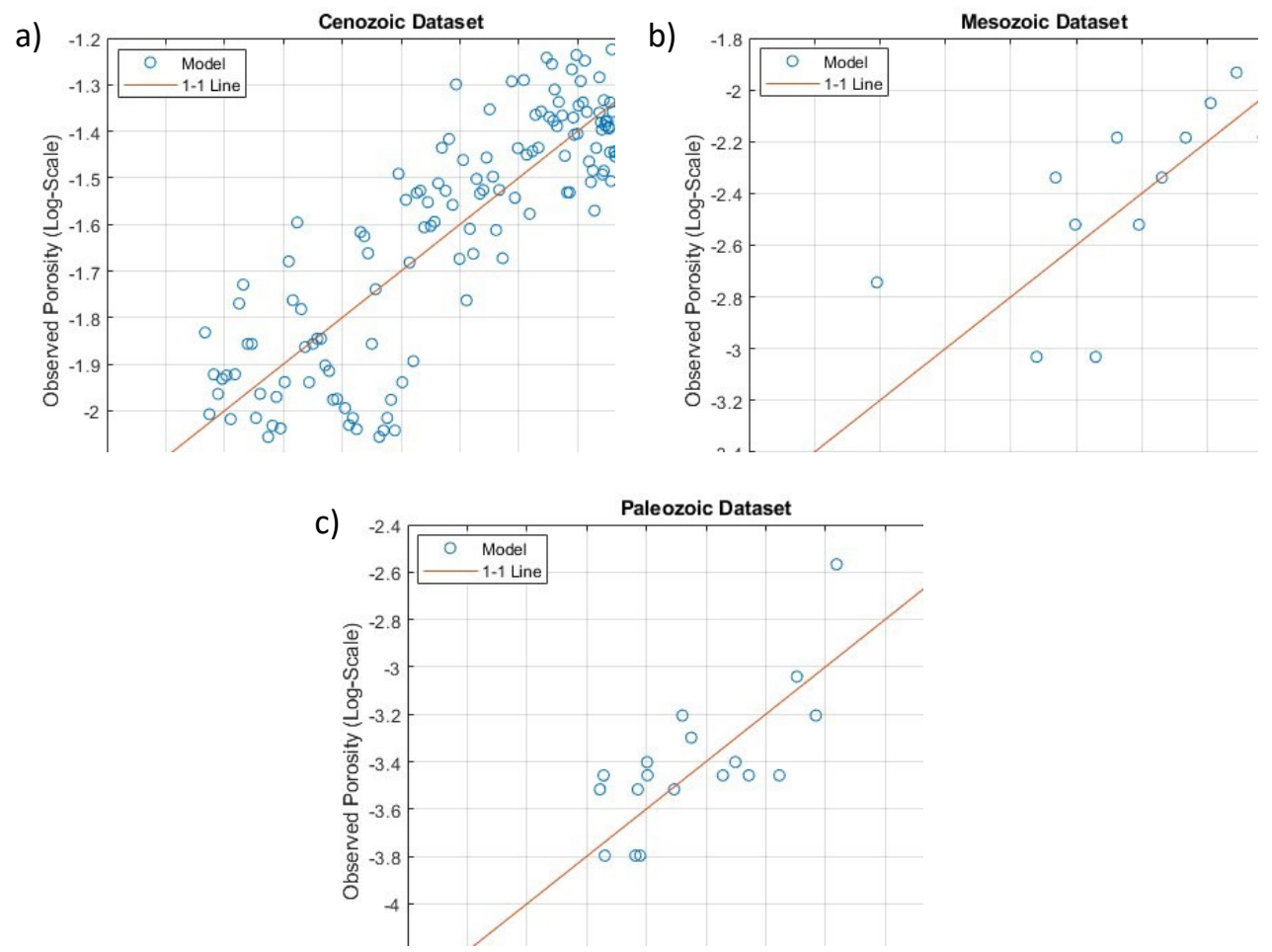

Figure 5. Validation of new emperical model for each geological age dataset (a) Cenozoic Dataset,

(b) Mesozoic Dataset, (c) Paleozoic Dataset

\subsection{Three Dimensional (3D) Model of Standard Compaction for Thailand Shales}

The influence of geological ages on the shale compaction is explored explicitly in Figure 4, an understanding of different geological ages is important for the reliability of the shale compaction. 3D model (porosity as a function of depth and geological age) of standard shale compaction is fitted to all data because a popular model of Athy [7] fails to account for the porosity-depth variations Figure 2, The empirical equation (9) of a 3D standard model for Thailand shale compaction is expressed:

$$
\ln \phi=-0.6683-0.0012 z-0.0052 T
$$




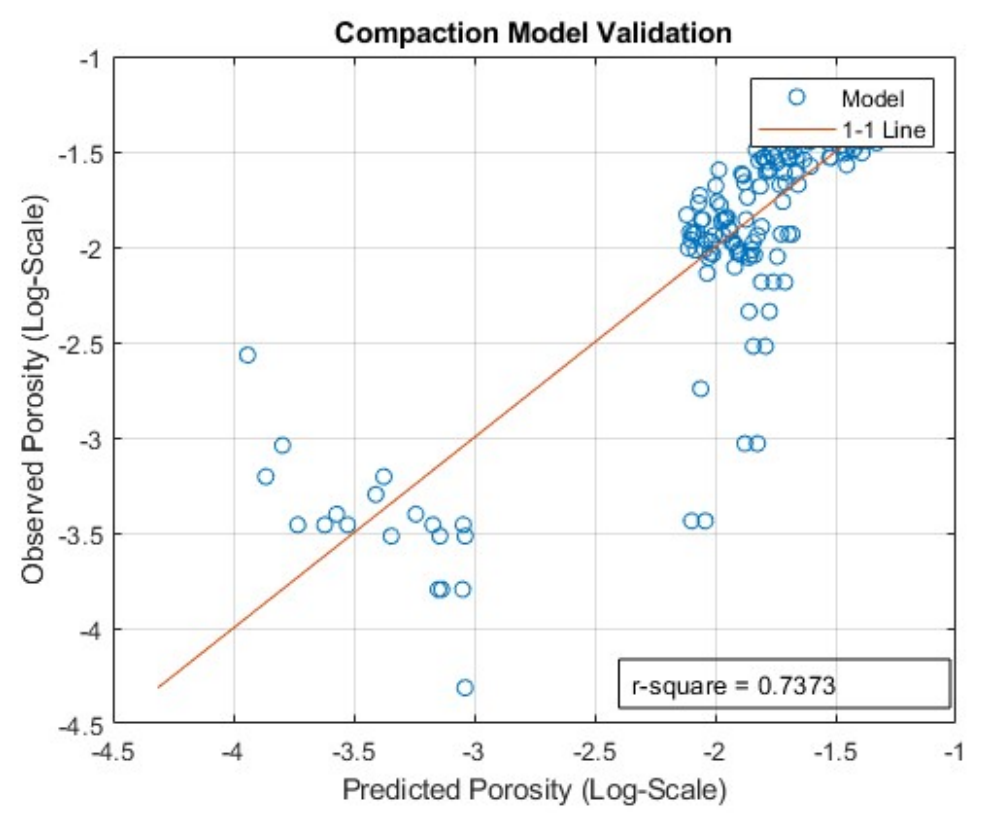

Figure 6. The validation of an empirical model for all datasets

Figure 6 shows the full porosity range relating to the depth and the geological age is better described by Eq. (10), this Eq. (10) fits the entire data best at r-square of 0.74. A standard model of shale compaction in this study supported the proposed model of an earlier study by Puttiwongrak et al. [9]. The research findings here are consistent with the work of Puttiwongrak et al. [9] which suggests that shales require geological age data as a parameter of compaction data to better fit the compaction model. The initial porosity of the Eq. (10) gave 51\% that is very close to 55.9\% from Puttiwongrak et al. [9], other model parameters are compared to the Puttiwongrak et al.'s study [9] as shown in Table 2. The comparison result is judged to be reasonable when the initial porosity and compaction coefficients are close to each other, except the compaction coefficient of burial depth. It can thus confirm that the burial depth alone is not sufficient to describe the shape of the shale compaction curve.

The observed porosity and burial depth data were plotted with geological age data calculated using equation (5) in a three-dimensional (3D) plot as shown in Figure 7. The 3D curve fitting provides an initial porosity of 51\% and r-square equals 0.7704 , which very similar to that given by Eq. (10).

Table 2. The comparison between 3D compaction models

\begin{tabular}{lcc}
\hline \multicolumn{1}{c}{ Parameter } & $\begin{array}{c}\text { The model purposed by this } \\
\text { study }\end{array}$ & $\begin{array}{c}\text { The model of Put- } \\
\text { tiwongrak et al. [9] }\end{array}$ \\
\hline $\begin{array}{l}\text { Initial porosity, } \phi_{0} \\
\begin{array}{l}\text { Compaction Coefficient } \\
\text { of Burial Depth }\end{array}\end{array}$ & $51.0 \%$ & $55.9 \%$ \\
$\begin{array}{l}\text { Compaction Coefficient } \\
\text { of Geologic Time } \\
\text { r-square }\end{array}$ & 0.0012 & 0.4000 \\
\hline
\end{tabular}




\section{D Plot of Porosity-Buiral Depth-Geological Age}

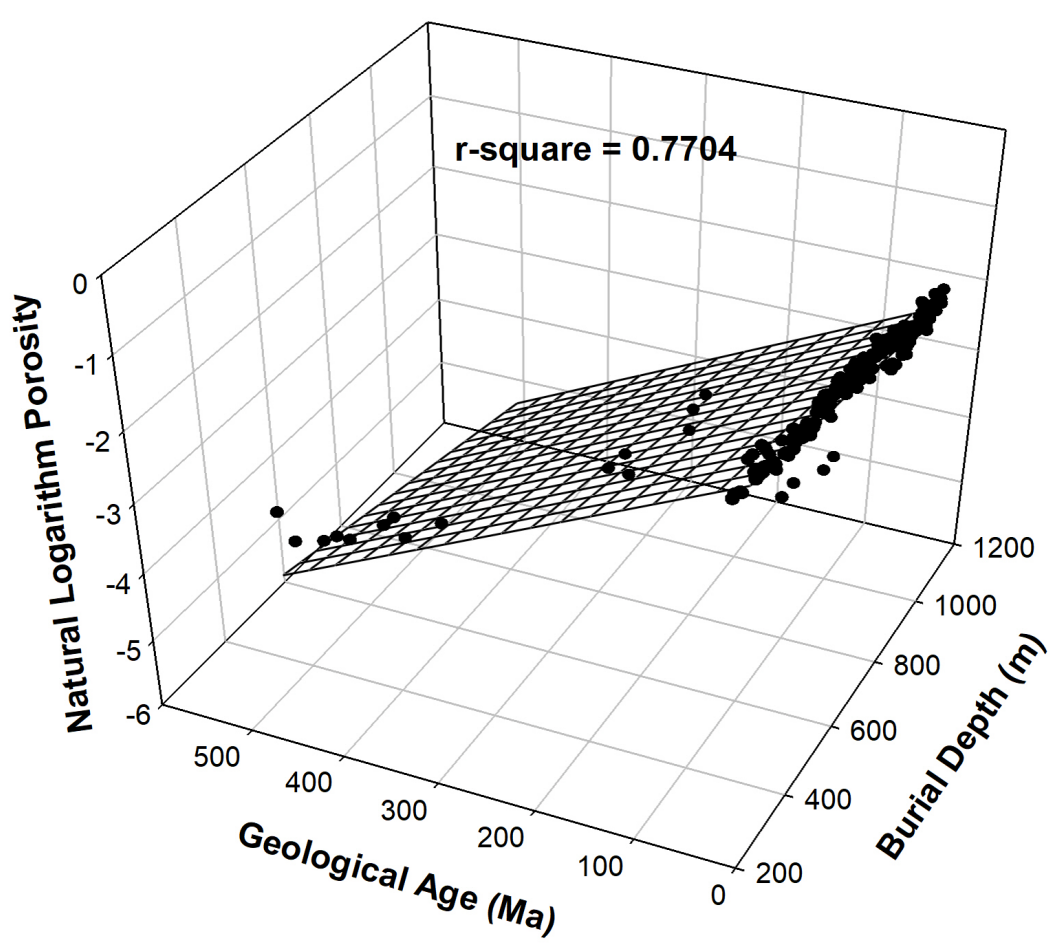

Figure 7. Three Dimension (3D) plot of porosity, burial depth, and geological age in $\mathrm{Ma}$ (million years ago).

\section{Conclusions}

This study has explored and insisted on the 3D empirical model in the relation among porosity, burial depth, and geological age in the shaly formation of northeastern Thailand from the analysis of the large datasets. The main conclusions of this study are:

- The numeric data of geological age in a shaly formation may be difficult to obtain, but they are derived from the relationship of velocity, depth, and geological age proposed by Faust [21].

- The conventional exponentially model of shale compaction from Athy [7] was not fitted to the data in order to obtain a compaction curve without an analysis of geological age classification.

- The research findings of this study observed that the compaction trend of porosity reduction, especially in the shallow part, is different in each geological age for shales.

- The significant relationship among porosity, burial depth, and geological age of the shaly formation throughout the study area provides a framework for the compaction curve of the effect of geological time.

- The mathematical formalisms of the compaction model on shale data can be established by the 3D empirical analysis of the relationship among porosity, burial depth, and geological age.

- The standard curve of the compaction data was found for northeastern Thailand shales using a 3D empirical model of the relationship among porosity, burial depth, and geological age, it is the most comprehensive state of the art of published work of Puttiwongrak et al. [9]. 
Although this study makes a clear relation on compaction in shales among porosity, burial depth, and geological age of northeastern Thailand, the new compaction model is fitted to the data rather than the classical paradigm [7]. However, the laboratory measurements of time effect on shale compaction are very rare as the limitation of sophisticated experiment and procedures, the further work should be focused on the effect of time in laboratory scale.

Author Contributions: A.P.: Conceptualization, Writing-review \& editing; S.N.: Data collection, Formal analysis, Writing-original draft; C.B.: Data collection; P.H.G.: Supervision, Resources; S.V.: Writing-review \& editing; T.S.: Validation, Resources.

Funding: This research received no external funding

Acknowledgments: The authors thank the Department of Mineral and Fuel of Thailand for provided the shale compaction data of northeastern Thailand. Special thanks are also due to PSU English Clinic for English proofreading.

Conflicts of Interest: The authors declare no conflict of interest.

\section{References}

1. Xia, L.; Liu, Z.; Li, W.; Lu, C.; Yang, X.; Liu, M.; Ternary analytic porosity-reduction model of sandstone compaction trend and its significance in petroleum geology: A case study of tight sandstones in Permian Lower Shihezi Formation of Shilijiahan area, Ordos Basin, China, Petrol. Explor. Develop. 2018, 45(2), 290-301.

2. Scherer, M.; Parameters influencing porosity in sandstones: A model for sandstone porosity prediction. AAPG Bulletin, 1987, 71(5), 485-491.

3. Giles, M.R.; Indrelid, S.L.; James, D.M.D.; Compaction: The great unknown in basin modelling. Geol. Soc. Spec. Publ. 1998, 141(1), 15-43.

4. Asia Pacific Energy Research Centre, Pathways to Shale Gas Development in Asia-Pacific; Japan, 2015.

5. Izumi, K.; Suzuki, R.; Inui, M.; Estimating the Degree of Mudstone Compactional Thinning: Empirical Relationship Between Mudstone Compaction and Geochemical Compositions. Trans. Kokushikan Unic. Sci, Eng. 2017, 10, 29-37.

6. Marcussen, Ø.; Faleide, J. I.; Jahren, J.; Bjørlykke K.; Mudstone compaction curves in basin modelling: a study of Mesozoic and Cenozoic Sediments in the northern North Sea. Basin Res., 2010, 22(3), 324-340.

7. Athy L.F.; Density, Porosity, and Compaction of Sedimentary Rocks. AAPG Bulletin, 1930, 14(1), 1-24.

8. Dasgupta, T.; Mukherjee, S.; Compaction of Sediments and Different Compaction Models. In Sediment Compaction and Applications in Petroleum Geoscience, $1^{\text {st }}$ ed.; Swennen, R., Eds.; Springer Nature Switzerland AG: Cham, Switzerland, 2020. pp. 1-7.

9. Puttiwongrak, A.; Vann, S.; Giao, P. H.; An Easily Used Mathematical Model of Porosity Change with Depth and Geologic Time in Deep Shale Compaction, Int. J. GEOMATE. 2020, 19(73), 108-115.

10. Mondol N. H., Bjorlykke K., Jahren J., and Hoeg K., Experimental Mechanical Compaction of Clay Mineral AggregatesChanges in Physical Properties of Mudstones during Durial, Mar. Petrol. Geol. 2007, 24(5), 289-311.

11. Puttiwongrak, A.; Honda, H.; Matsuoka, T.; Yamada, T.; Compaction curve with consideration of time and temperature effects for mudstones, Geotech. Eng. Journal of the SEAGS \& AGSSEA, 2013, 44 (1), 34-39

12. Peltonen et al., 2008 Peltonen, C.; Marcussen, Ø.; Bjørlykke, K.; Jahren, J.; 2008, Clay mineral diagenesis and quartz cementation in mudstones: The effects of smectite toillite transformation of rock properties, Mar. Petrol. Geol. 2008, 26(6), 887-898.

13. Pervukhina, M.; Rasolofosaon, P. N. J.; Compaction trend versus seismic anisotropy in shaly formations. Geophys. Prospect., 2017, 65(5), 1351-1365.

14. Revil, A.; Grauls, D.; Brevart, O.; Mechanical compaction of sand/clay mixtures. J. Geophys. Res., 2002, 107(B11), 11-1 - 11-15.

15. Nygård, R.; Gutierrez, M.; Gautam, R.; Høeg, K.; 2004. Compaction behavior of argillaceous sediments as function of diagenesis, Mar. and Petrol. Geol. 2004. 21(3), 349-362.

16. Burst J.F.; Diagenesis of Gulf Coast Clayey Sediments and its Possible Relation to Petroleum Migration, AAPG Bulletin, 1969, 53(1), 73-93.

17. Department of Mineral Resources, Mineral Fuels Division Annual Report 1995 Petroleum Activities in Thailand, Bangkok, Thailand.

18. Introduction: Thailand Petroleum Province. Available online: https://dmf.go.th/bid20/petro province.html (accessed on 28 December 2020)

19. U.S Energy Information Administration, Technically Recoverable Shale Oil and Shale Gas Resources: Thailand, U.S. Department of Energy, Washington D.C., 2015.

20. Broichhausen et al., 2005. Broichhausen, H.; Littke, R.; Hantschel, T.; Mudstone compaction and its influence on overpressure generation, elucidated by a 3D case study in the North Sea. Int. J. Earth Sci., 2005, 94, 956-978.

21. Faust, L. Y.; Seismic Velocity as a function of depth and geological time, Geophysics, 1951, 16(2), $192-206$. 